\title{
Controle de doenças foliares e de flores e qualidade pós-colheita do mo- rangueiro tratado com Saccharomyces cerevisiae
}

\author{
Alfredo de Gouvea ${ }^{1}$; Odair J Kuhn²; Sérgio M Mazaro'; Louise L May-De Mio³; Cícero Deschamps ${ }^{3}$; Luiz \\ A Biasi ${ }^{3}$; Vânia de C Fonseca ${ }^{4}$ \\ ${ }^{1}$ UTFPR, C. postal 157, 85660-000 Dois Vizinhos-PR; 2ESALQ-Depto. Entomologia, Fitopatologia e Zoologia Agrícola, C. Postal 09, \\ 13418-900 Piracicaba-SP; ${ }^{3}$ UFPR-Depto. Fitotecnia e Fitossanitarismo, SCA, C. Postal 19061, 81531-990 Curitiba-PR. ${ }^{4}$ UFPR-Setor de \\ Tecnologia, Centro Politécnico, C. Postal 19011,81531-990 Curitiba-PR; alfredo@utfpr.edu.br; ojkuhn@esalq.usp.br; sergio@utfpr.edu. \\ br; maydemio@ufpr.br; cicero@ufpr.br; biasi@ufpr.b; cassifonseca@yahoo.com.br
}

\section{RESUMO}

O efeito de diferentes preparações de Saccharomyces cerevisiae foi avaliado sobre o desenvolvimento das doenças do morangueiro, como mancha-de-micosferela (Mycosphaerella fragariae), manchade-dendrofoma (Dendrophoma obscurans) e flor-preta (Colletotrichum acutatum) além da qualidade pós-colheita dos frutos. O trabalho foi realizado entre 2004 e 2005 na Universidade Tecnológica Federal do Paraná, Campus Dois Vizinhos. Os tratamentos consistiram de pulverizações semanais de cinco diferentes preparados a partir da levedura S. cerevisiae: suspensão com fermento biológico fresco comercial, suspensão de células de levedura, suspensão autoclavada de células, filtrado de cultura em meio líquido e Agro-MOS ${ }^{\circledR}$, produto comercial formulado a partir da levedura, além da testemunha com água destilada e do tratamento controle com fungicidas. Nenhuma das preparações apresentou efeito contra a mancha-de-micosferela; preparações com a presença de células vivas e o produto Agro-MOS ${ }^{\circledR}$ apresentaram efeito contra mancha-de-dendrofoma; preparações com suspensão do produto comercial e filtrado de cultura líquida reduziram a incidência de flor-preta em flores e frutos. Preparações de $S$. cerevisiae com suspensão de células, suspensão autoclavada de células e filtrado de cultura líquida promoveram aumento na produtividade dos morangueiros que variou de 589,6 a 617,8 g planta $^{-1}$. Preparações de $S$. cerevisiae, com presença de células vivas ou não, alteraram o metabolismo do morangueiro, aumentando a atividade das enzimas quitinase e glucanase, envolvidas na resistência sistêmica adquirida. Todos os tratamentos, com exceção do tratamento com suspensão autoclavada de células, reduziram a incidência de mofo-cinzento em pós-colheita de frutos.

Palavras-chave: Fragaria $x$ ananassa, antibiose, antagonismo, resistência sistêmica adquirida.

\begin{abstract}
Control of leaf and flower diseases and postharvest quality of strawberry plants treated with Saccharomyces cerevisiae

The effect of Saccharomyces cerevisiae was evaluated on the development of strawberry diseases and postharvest quality of fruits. The research was carried out in 2004 and 2005 in Paraná State, Brazil. Five different preparations of the yeast S. cerevisiae (a suspension of commercial fresh biological yeast for bakery, a suspension of yeast cells, a suspension of autoclaved cells, a filtered yeast liquid culture and the commercial product Agro-MOS $®$ ) were compared to control treatments (distilled water spraying and another one with fungicides). None of the preparations were effective against the mycosphaerella leaf spot (Mycosphaerella fragariae); preparations with living cells and the product Agro-MOS $®$ showed effect against leaf blight (Dendrophoma obscurans); suspension of the bakery yeast and the filtered liquid culture reduced the incidence of anthracnose (Colletotrichum acutatum) in flowers and fruits. Preparations of S. cerevisiae with suspension of cells, suspension of autoclaved cells and filtered liquid culture increased the productivity of the strawberry plants, which ranged from 589.6 to 617.8 g plant- 1 . The preparations of S. cerevisiae, with living cells or not, modified the plant metabolism, improving the activity of the chitinase and glucanase enzymes, which are involved in the acquired systemic resistance. Except for the treatment with suspension of autoclaved cells, the other preparations reduced the incidence of gray mould (Botrytis cinerea) in the postharvest of fruits.
\end{abstract}

Keywords: Fragaria $x$ ananassa, antibiosis, antagonism, sistemic acquired resistance.

(Recebido para publicação em 15 de abril de 2008; aceito em 12 de agosto de 2009) (Received in April 15, 2008; accepted in August 12, 2009)

\begin{abstract}
A cultura do morangueiro desempenha um importante papel socioeconômico, pois é desenvolvida em pequenas propriedades e com necessidade de mão-de-obra em todo seu ciclo, gerando emprego e renda. Entretanto, com o crescimento da área explorada com o morangueiro intensificam-se os problemas fitossanitários na cultura (Reichert \& Madial, 2003).

Um dos problemas atuais de maior gravidade é a alta incidência de molés-
\end{abstract}

tias. A forma predominante de controle destas doenças é com o uso intensivo de agrotóxicos, o que tem levado a graves problemas, como surgimento de populações de patógenos resistentes a fungicidas, aumento do custo de produção, resistência ao consumo do fruto ocasionada pela conscientização da população em geral dos malefícios desta prática, além dos problemas de ordem ambiental (Tanaka et al., 1997; Fernandes Jr. et al., 2002).
Diante da necessidade de minimizar esse problema e atender a demanda de alimentos de melhor qualidade, produtores e pesquisadores buscam formas alternativas de manejo fitossanitário. Dentre as diversas estratégias, destacam-se o controle biológico e a indução de resistência a doenças de plantas. Em ambas as alternativas a levedura Saccharomyces cerevisiae é apontada por diversos autores como tendo um grande potencial de utilização 
(Cardoso Filho, 2003, 2004; Fialho, 2004; Bonaldo, 2005).

A levedura é estudada na proteção de plantas de diversas espécies vegetais atuando por diferentes mecanismos. $S$. cerevisiae pode induzir resistência em plantas contra doenças, além de atuar diretamente sobre o patógeno por antibiose ou competição.

Foram encontrados resultados positivos no controle de doenças e no aumento da produtividade. A competição por espaço e nutriente é apontada como um importante mecanismo pelo qual $S$. cerevisiae atua no controle de fitopatógenos, como no controle de Botrytis cinerea em kiwi (Cheah \& Hunt, 1994), de Fusarium sambucium em abóbora (Cucurbita maxima) (Cheah \& Marshall, 1995) e de Penicillium digitatum em limão (Cheah \& Tran, 1995).

Efeito antagônico por antibiose de $S$. cerevisiae sobre $C$. graminicola foi observado por Silva \& Pascholati (1992) em milho, onde suspensão de células do produto comercial e o seu filtrado reduziu o desenvolvimento do patógeno e a manifestação do sintoma, sendo esta proteção não sistêmica e termoinstável.

A antibiose também foi o mecanismo provável de ação de $S$. cerevisiae sobre Hemileia vastatrix em café (Roveratti, 1989), Botrytis cinerea em Eucalyptus sp. (Lopes, 2001) e sobre Exserohilum turcicum em milho (Stangarlin \& Paschoalati, 1994). S. cerevisiae in vitro também afetou o desenvolvimento, reduzindo a germinação e formação de apressório por Guignardia citricarpa, agente causal da pinta preta em citros (Cardoso Filho, 2003).

Fialho (2004) constatou que o efeito inibidor do crescimento de G. citricarpa está associado a um composto volátil produzido por $S$. cerevisiae. Cia (2005) observou que $S$. cerevisiae protegeu mamão contra $C$. gloeosporioides e a autora atribuiu o efeito da levedura sobre o patógeno à antibiose e competição.

Dantas et al. (2004), no entanto, obtiveram resultados semelhantes usando o produto AM obtido a partir da parede celular de $S$. cerevisiae, sendo esta proteção atribuída à resistência sistêmica adquirida.
Diante dos resultados positivos obtidos na proteção de plantas contra patógenos por $S$. cerevisiae e da inexistência de informação sobre o efeito da levedura sobre as doenças do morangueiro em condições de campo realizaram-se dois experimentos visando avaliar o efeito de diferentes preparados a partir de $S$. cerevisiae sobre o desenvolvimento de doenças do morangueiro, a qualidade pós-colheita de frutos e o mecanismo de ação da levedura no sistema patógenohospedeiro, bem como relacionar o resultados dos tratamentos com produtividade.

\section{MATERIAL E MÉTODOS}

Experimento 1 - Foi implantado, em maio de 2004, na UTFPR, Campus Dois Vizinhos, situada a $25^{\circ}, 42$ ', 52"' S e 53, 03', 94" W, a 519 metros acima do nível do mar. O solo local é do tipo Latossolo Vermelho Distroférrico Típico e o terreno apresenta em torno de 3\% de declividade média.

Trinta dias antes do plantio foi aplicado e devidamente incorporado calcário com base no resultado das análises químicas do solo e posteriormente incorporado. Utilizou-se o delineamento experimental blocos ao acaso com quatro repetições e 16 plantas por parcela.

As parcelas de 1,20 x 1,20 m, continham quatro fileiras de quatro plantas espaçadas de 0,30 m. Foi utilizada a cultivar Camarosa, em sistema de túnel baixo com irrigação por gotejamento. Foi colocado o mulching com filme de polietileno preto 30 dias após plantio.

A adubação de base foi realizada por ocasião do plantio e após a colocação do mulching passou-se a utilizar fertirrigação com base na recomendação para a cultura.

Os tratamentos consistiram na pulverização semanal da levedura $S$. cerevisiae em cinco diferentes preparações, sendo T1: suspensão com fermento biológico fresco comercial $\left(30 \mathrm{mg} \mathrm{mL}^{-1}\right)$; T2: suspensão de células de levedura (1 x $10^{5}$ células $\mathrm{mL}^{-1}$ ); T3: suspensão autoclavada de células ( 1 x $10^{5}$ células $\left.\mathrm{mL}^{-1}\right)$; T4: filtrado de cultura em meio líquido $\left(0,1 \mathrm{~mL} \mathrm{~mL}^{-1}\right)$; T5: Agro-MOS ${ }^{\circledR}$ (AM), produto formulado a partir da levedura, relatado como indutor de resistência a doenças em plantas (Dantas et al., 2004) (0,002 $\left.\mathrm{mL} \mathrm{mL}^{-1}\right)$; T6: testemunha (água); e T7: controle $(\mathrm{TM}+\mathrm{F}+\mathrm{I})$ que consistiu da aplicação de uma combinação de fungicidas a cada sete dias com uso de clorotalonil+tiofanatometílico $(0,0049 \%)$ até o florescimento e posteriormente alternou-se folpete $(0,00135 \%)$ e Iprodione $(0,0075 \%)$. As suspensões com fermento biológico fresco (T1) foram obtidas a partir do produto comercial Itaiquara ${ }^{\circledR}$, adquirido no comércio local semanalmente.

As preparações de S. cerevisiae (T2 e T3) foram obtidas de isolamento a partir do produto comercial e posteriormente cultivada em meio YEPG, contendo $10 \mathrm{~g}$ de extrato de levedura, $20 \mathrm{~g}$ de peptona, $20 \mathrm{~g}$ de glicose, $20 \mathrm{~g}$ de ágar e $1000 \mathrm{~mL}$ de água. Semanalmente, a levedura foi repicada para placas de Petri com o meio e mantidas a $26^{\circ} \mathrm{C}$ por $48 \mathrm{~h}$. Posteriormente, as células foram suspensas em água destilada e a concentração ajustada em 1 × $10^{5}$ células $\mathrm{mL}^{-1}$ com uso de câmara de Neubauer, sendo que parte da suspensão, destinado ao tratamento 3, foi autoclavada a $120^{\circ} \mathrm{C}$ por $20 \mathrm{~min}$.

Para obtenção do filtrado (T4) a levedura foi cultivada em estufa a $26^{\circ} \mathrm{C}$ sob agitação orbital (90 rpm) por 48 $\mathrm{h}$ em meio YEPG líquido. O material resultante foi esterilizado por meio de filtragem em membrana de nitrocelulose com diâmetro de poro de 0,2 $\mu \mathrm{m}$ e posteriormente diluído em água.

O inicio da aplicação dos tratamentos com a aplicação dos elicitores se deu 45 dias após o plantio e o volume de calda dos tratamentos e de água no tratamento testemunha foi em média de $30 \mathrm{~mL}$ por planta.

Para avaliação das doenças foliares mancha-de-micosferela causada por Mycosphaerella fragariae e mancha-dedendrofoma causada por Dedrophoma obscurans, foram realizadas, a cada 21 dias, a contagem do número de folhas com sintomas das doenças, considerando-se as quatro plantas centrais de cada parcela e a incidência definida pelo percentual de folhas atacadas em relação ao total de folhas das plantas avaliadas.

A partir da quarta avaliação as fo- 
lhas com sintomas de dendrofoma que vinham sendo avaliadas se desintegraram impossibilitando a continuidade da avaliação da doença, uma vez que não se observou o surgimento de novas lesões.

Com base nos dados obtidos foi determinada a área abaixo da curva de progresso da doença através da fórmula: $\mathrm{AACPD}=\Sigma\left[\left(\mathrm{I}_{\mathrm{i}}+\mathrm{I}_{\mathrm{i}+1}\right) / 2 .\left(\mathrm{T}_{\mathrm{i}+1}-\mathrm{T}_{\mathrm{i}}\right)\right]$, onde $\mathrm{AACPD}=$ área abaixo da curva de progresso da doença; $I_{i}=$ incidência na época da avaliação i e $\mathrm{T}_{\mathrm{i}}=$ idade da planta na época da avaliação $\mathrm{i}$.

Para avaliação da antracnose, cujo sintoma é conhecido como flor-preta, causada por Colletotrichum acutatum, foi efetuada a avaliação da incidência de sintomas típicos do ataque do patógeno, caracterizado pela necrose das flores e frutos jovens, deformações em frutos verdes e manchas deprimidas nos frutos maduros (Tanaka \& Passos, 2002).

Para avaliar o efeito da doença sobre a produtividade considerou-se o número médio de frutos colhidos nas colheitas realizadas na semana anterior e posterior à data de avaliação.

Para a avaliação da produtividade e da qualidade pós-colheita, os frutos foram colhidos em média a cada três dias, acondicionados em embalagens identificadas e no laboratório, contados, selecionados, eliminando-se aqueles fora do padrão do ponto de maturação ou com ferimentos e pesados em balança de precisão.

A produtividade média foi obtida somando-se a massa dos frutos de todas as colheitas e dividindo-se pelo número de plantas da parcela. Os ensaios para análise em pós-colheita foram realizados duas vezes, sendo que na segunda os frutos foram artificialmente feridos em dois lugares.

Os ferimentos situavam-se em lados opostos na região equatorial dos frutos e possuíam $2 \mathrm{~mm}$ de diâmetro e $5 \mathrm{~mm}$ de profundidade. Os frutos foram mantidos em temperatura ambiente por cinco dias e, posteriormente, efetuaram-se as avaliações físico-químicas pós-colheita.

As avaliações foram realizadas com quatro repetições e a unidade experimental composta por 10 frutos. As análises físico-químicas dos frutos, incidência de podridões, firmeza de polpa e acidez titulável foram realizadas na UTFPR, Campus Dois Vizinhos-PR. A avaliação da incidência de podridões foi realizada pela análise visual e expressa em percentual de frutas com sintomas de podridão por $B$. cinerea, sendo consideradas podres aquelas que apresentavam sintomas e sinais típicos de ataque do patógeno.

A firmeza de polpa foi determinada com uso de penetrômetro manual de alta precisão com leitura de 0 a 14 libras, munido de uma ponteira de 7,9 mm, perfurando-se cada fruta em dois lados opostos na região equatorial. $\mathrm{O}$ valor foi expresso em libras $/ \mathrm{cm}^{2}$ e transformado para Newton.

A acidez titulável foi determinada em uma amostra de $10 \mathrm{~mL}$ de suco dos frutos diluída em $100 \mathrm{~mL}$ de água destilada e titulada com uma solução de hidróxido de sódio $0,1 \mathrm{~N}$ até $\mathrm{pH} 8,1$ e o resultado expresso em meq $100 \mathrm{~mL}^{-1}$.

O teor de sólidos solúveis totais foi determinado por refratometria manual, com posterior correção do efeito da temperatura e o resultado expresso em ${ }^{\circ}$ Brix.

Experimento 2 - para avaliação das possíveis alterações bioquímicas ocorridas no processo de proteção da planta o experimento foi repetido com as mesmas características em 2005.

As preparações de $S$. cerevisiae corresponderam aos tratamentos descritos no Experimento 1, exceto o T1 e alterando-se o T7 que neste caso recebeu pulverizações com clorotalonil+tiofanatometílico (0,0049\%). A aplicação dos tratamentos ocorreu 45 dias após o plantio.

As amostras consistiram em discos foliares com $2 \mathrm{~cm}$ de diâmetro da região mediana de folhas completamente expandidas coletadas 24, 72, 120 e 168 $\mathrm{h}$ após a aplicação. Imediatamente após as coletas as amostras foram congeladas em nitrogênio líquido e armazenadas em freezer a $-20^{\circ} \mathrm{C}$ até as avaliações. As análises foram realizadas em laboratório da ESALQ, em Piracicaba-SP.

Para dosagem de proteínas totais, as amostras de tecido foliar foram maceradas em almofariz com $10 \mathrm{~mL}$ de tampão fosfato 0,2 M ( $\mathrm{pH} 7,5)$. Em seguida, o material foi centrifugado $(14.000 \mathrm{~g}$ por $10 \mathrm{~min}$. a $4^{\circ} \mathrm{C}$ ) e o sobrenadante coletado.

Para quantificação do conteúdo total de proteínas nas amostras foi empregado o teste de Bradford, com leitura em espectrofotômetro, modelo UV-1601Shimadzu a $630 \mathrm{~nm}$, usando soro albumina bovina como solução padrão. Para dosagem das atividades de quitinases e $\beta$-1,3-glucanases as amostras foram maceradas em 4,0 mL de tampão de extração, acetato $100 \mathrm{mM}(\mathrm{pH} \mathrm{5,0)}$, com posterior centrifugação (20.000 $g$ por $25 \mathrm{~min}$. a $4^{\circ} \mathrm{C}$ ). $\mathrm{O}$ sobrenadante (extrato proteico) foi coletado e $200 \mu \mathrm{L}$ utilizados para a avaliação da atividade das enzimas.

A atividade enzimática das quitinases foi avaliada por meio da liberação de fragmentos solúveis de quitina carboximetilada, marcada com remazol brilhante violeta (CM-chitin-RBV). Para tanto, $200 \mu \mathrm{L}$ do extrato proteico foram misturados a $600 \mu \mathrm{L}$ do mesmo tampão de extração e a $200 \mu \mathrm{L}$ de "CM-chitin-RBV" (2,0 mg mL-1). Após incubação por $20 \mathrm{~min}$. a $40^{\circ} \mathrm{C}$, a reação foi paralisada com a adição de $200 \mu \mathrm{L}$ de solução de $\mathrm{HCl}$ 1,0 M, seguida de resfriamento em gelo e centrifugação a $10.000 \mathrm{~g}$ por 5 minutos.

A absorbância a $550 \mathrm{~nm}$ do sobrenadante foi determinada como referência e os resultados foram expressos em unidades de absorbância/min/g de proteína, descontando-se os valores de absorbância do controle $(800 \mu \mathrm{L}$ de tampão de extração e $200 \mu \mathrm{L}$ de "CMchitin-RBV”) (Stangarlin et al., 2000).

Para a determinação espectrofotométrica das atividades de $\beta$-1,3-glucanases nos extratos foi utilizado como substrato uma solução de carboximetilcurdlanremazol azul brilhante (CM-CurdlanRBB $4 \mathrm{mg} \mathrm{mL}{ }^{-1}$, Loewe Biochemica $\mathrm{GmbH})$, de acordo com metodologia desenvolvida por Wirth \& Wolf(1992) e com o procedimento descrito por Guzzo $\&$ Martins (1996). Para tanto, $200 \mu \mathrm{L}$ do extrato protéico foi misturado com $600 \mu \mathrm{L}$ do mesmo tampão de extração e $200 \mu \mathrm{L}$ de CM-curdlan-RBB (4,0 $\left.\mathrm{mg} \cdot \mathrm{mL}^{-1}\right)$. Após incubação por $20 \mathrm{~min}$. a $40^{\circ} \mathrm{C}$, a reação foi paralisada com a 
adição de $200 \mu \mathrm{L}$ de solução de $\mathrm{HCl}$ 1,0 $\mathrm{M}$, seguida de resfriamento em gelo e centrifugação a $10.000 \mathrm{~g}$ por $5 \mathrm{~min}$. A absorbância do sobrenadante foi determinada a $600 \mathrm{~nm}$. Os resultados foram expressos em unidades de absorbância/ $\mathrm{min} / \mathrm{g}$ de proteína.

Para avaliação dos resultados foi realizada a análise da variância, utilizando-se o teste $\mathrm{F}$ e, posteriormente o teste de Duncan ao nível de 5\% de probabilidade. Para análise da diferença entre as médias, utilizou-se o programa estatístico SASM ${ }^{\circledR}$ Versão 3.2.4.

\section{RESULTADOS E DISCUSSÃO}

Nenhuma das preparações de $S$. cerevisiae testadas interferiu no desenvolvimento da mancha-de-micosferela (Tabela 1), indicando que o patógeno não é afetado por nenhum dos mecanismos de ação da levedura.

$\mathrm{O}$ tratamento controle $(\mathrm{TM}+\mathrm{F}+\mathrm{I})$ feito com a utilização de fungicidas, no entanto, apresentou efeito sobre a doença, apresentando a AACPD inferior aos demais tratamentos. Apesar da significativa diferença entre o tratamento com fungicidas e os demais tratamentos, quando a análise é feita comparando-se a AACPD, pode-se notar, pela baixa severidade da doença (dados não apresentados), que a cultivar utilizada no experimento apresenta resistência contra a doença, independentemente de tratamentos, sendo que durante todo ciclo da cultura a área foliar afetada

Tabela 1. Área abaixo da curva de progresso da doença (AACPD) da incidência de mancha-de-micosferela (Mycosphaerella fragariae), de mancha-de-dendrofoma (Dendrophoma obscurans) e produtividade de morangueiro, cultivar Camarosa, tratado com diferentes preparações de Saccharomyces cerevisiae (area under the disease progress curve (AUDPC) of the incidence of mycosphaerella leaf spot (Mycosphaerella fragariae), leaf blight (Dendrophoma obscurans) and productivity of the strawberry plants, cultivar Camarosa, treated with different preparations of Saccharomyces cerevisiae). Dois Vizinhos, UTFPR, 2004.

\begin{tabular}{|c|c|c|c|c|c|}
\hline \multirow{2}{*}{ Tratamento } & \multicolumn{2}{|c|}{ AACPD } & \multicolumn{3}{|c|}{ Produtividade } \\
\hline & Micosferela & Dendrofoma & g fruto ${ }^{-1}$ & fruto planta $^{-1}$ & g planta $^{-1}$ \\
\hline Levedura comercial & $2183 a b c$ & $218 \mathrm{~b}$ & $14,9 \quad b$ & 35,9 bc & $536,3 \mathrm{abc}$ \\
\hline Suspensão de células & $1947 \quad \mathrm{c}$ & $255 \mathrm{~b}$ & $15,4 \mathrm{ab}$ & $40,1 \mathrm{a}$ & 617,8 a \\
\hline Susp. Autoclavada de cél. & $1980 \mathrm{bc}$ & $311 \mathrm{a}$ & $16,0 \mathrm{a}$ & $37,7 \mathrm{abc}$ & $604,7 \mathrm{a}$ \\
\hline Filtrado de cultura líquida & $2453 \mathrm{ab}$ & $311 \mathrm{a}$ & $15,1 \mathrm{ab}$ & $39,0 \mathrm{ab}$ & $589,6 \mathrm{ab}$ \\
\hline Agro-MOS ${ }^{\circledR}$ & $2547 \mathrm{a}$ & $258 \mathrm{~b}$ & $14,9 \mathrm{~b}$ & $34,0 \quad \mathrm{c}$ & $506,7 \mathrm{bc}$ \\
\hline Testemunha & $2146 \mathrm{abc}$ & $370 \mathrm{a}$ & $15,0 \quad b$ & $33,6 \quad \mathrm{c}$ & $505,6 \quad \mathrm{c}$ \\
\hline Controle químico & 1271 & $198 \mathrm{~b}$ & $15,5 \mathrm{ab}$ & 35,0 bc & $543,7 \mathrm{abc}$ \\
\hline CV (\%) & 10,3 & 13,4 & 1,9 & 3,6 & 4,8 \\
\hline
\end{tabular}

Médias seguidas de mesma letra na coluna não diferem entre si, teste Duncan, $\mathrm{p}<0,05$ (means followed by the same letter in the column did not differ from each other, Duncan's test, $\mathrm{p}<0,05)$. Controle químico = clorotalonil+tiofanato-metílico, folpete e iprodione.

não ultrapassou $0,75 \%$ em nenhuma das repetições.

Na avaliação da AACPD da manchade-dendrofoma, constatou-se que a aplicação de $S$. cerevisiae na forma de levedura comercial e suspensão de células se destacaram, apresentando, semelhantemente ao tratamento com $\mathrm{TM}+\mathrm{F}+\mathrm{I}$, melhor resultado que o tratamento testemunha (Tabela 1). Estes dados indicam que a presença de células vivas da levedura foi determinante para o efeito sobre D. obscurans e que a competição foi possivelmente o mecanismo mais importante envolvido no processo de defesa da planta contra o patógeno.

De acordo com os resultados obtidos, pode ter havido participação da "Resistência Sistêmica Adquirida" (RSA) na redução da mancha-de-dendrofoma através da indução do aumento da atividade das enzimas quitinases e $\beta$-1,3-glucanases (Figura 1).

As quitinases e glucanases são proteínas relacionadas com a patogênese (PRP's) que possuem capacidade de hidrolizar células fúngicas, agindo diretamente sobre o patógeno e ou liberando fragmentos oligossacarídicos do fungo ou da parede celular da planta que elicitam respostas secundárias de defesa.

Vários trabalhos demonstram a redução de doenças associado ao aumento na atividade destas enzimas após indução por agentes bióticos e abióticos (Van Loon et al., 2006). O tratamento com $\mathrm{AM}$, sem a presença de células vivas da levedura, se destacou na indução do aumento na atividade das PRP's e apresentou um resultado semelhante aos tratamentos, onde as células vivas, possivelmente, tenham atuado por competição, além de ter também induzido resistência na planta.
O filtrado de cultura líquida de $S$. cerevisiae proporcionou os melhores resultados na avaliação da incidência da flor-preta em flores e em frutos (Tabela 2). Considerando-se que este tratamento não induziu o aumento da atividade das PRP's (Figura 1), provavelmente, seu efeito foi devido à antibiose, ou seja, algum composto originado no processo de crescimento da levedura atou negativamente sobre o desenvolvimento do patógeno.

O tratamento com a levedura na forma de fermento comercial também apresentou efeito sobre a flor-preta. De acordo com Piccinin et al. (2005), espécies do gênero Colletotrichum precisam de fonte de energia externa ao conídio para germinarem. Assim, $S$. cerevisiae poderia ter atuado contra o patógenos competindo por fatores vitais no filoplano. No entanto, o fato de que 
Tabela 2. Incidência de flor-preta (Colletotrichum acutatum) em flores e frutos de morango, cultivar Camarosa, tratado com diferentes preparações de Saccharomyces cerevisiae e número médio de frutos colhidos na época da avaliação (incidence of anthracnose (Colletotrichum acutatum) in flowers and fruits of strawberry, cultivar Camarosa, treated with different preparations of Saccharomyces cerevisiae and average number of fruits harvested at the evaluation time). Dois Vizinhos, UTFPR, 2004.

\begin{tabular}{lllll}
\hline \multirow{2}{*}{ Tratamento } & Frutos/ & \multicolumn{3}{c}{ Incidência de flor-preta (\%) } \\
\cline { 3 - 6 } & planta & Flores & Frutos & Média \\
\hline Levedura comercial & $2,1 \mathrm{ab}$ & $16,5 \mathrm{~b}$ & $13,8 \mathrm{ab}$ & $15,2 \mathrm{bc}$ \\
Suspensão de células & $2,5 \mathrm{a}$ & $30,3 \mathrm{ab}$ & $18,8 \mathrm{ab}$ & $24,5 \mathrm{ab}$ \\
Suspensão autoclavada de células & $2,2 \mathrm{ab}$ & $36,3 \mathrm{a}$ & $23,3 \mathrm{a}$ & $29,8 \mathrm{a}$ \\
Filtrado de cultura líquida & $2,5 \mathrm{a}$ & $16,6 \mathrm{~b}$ & $10,7 \mathrm{~b}$ & $13,6 \quad \mathrm{c}$ \\
Agro-MOS & $1,9 \mathrm{~b}$ & $23,7 \mathrm{ab}$ & $18,0 \mathrm{ab}$ & $20,8 \mathrm{abc}$ \\
Testemunha & $1,9 \mathrm{~b}$ & $33,6 \mathrm{ab}$ & $18,8 \mathrm{ab}$ & $26,2 \mathrm{a}$ \\
Controle químico & $2,1 \mathrm{ab}$ & $23,6 \mathrm{ab}$ & $20,2 \mathrm{a}$ & $21,9 \mathrm{abc}$ \\
\hline CV (\%) & 14,2 & 25,5 & 19,4 & 17,1 \\
\hline
\end{tabular}

Médias seguidas de mesma letra na coluna não diferem entre si, teste Duncan, $p<0,05$ (means followed by the same letter in the column did not differ from each other, Duncan's test, $\mathrm{p}<0,05)$. Controle químico $=$ clorotalonil+tiofanato-metílico, folpete e iprodione.

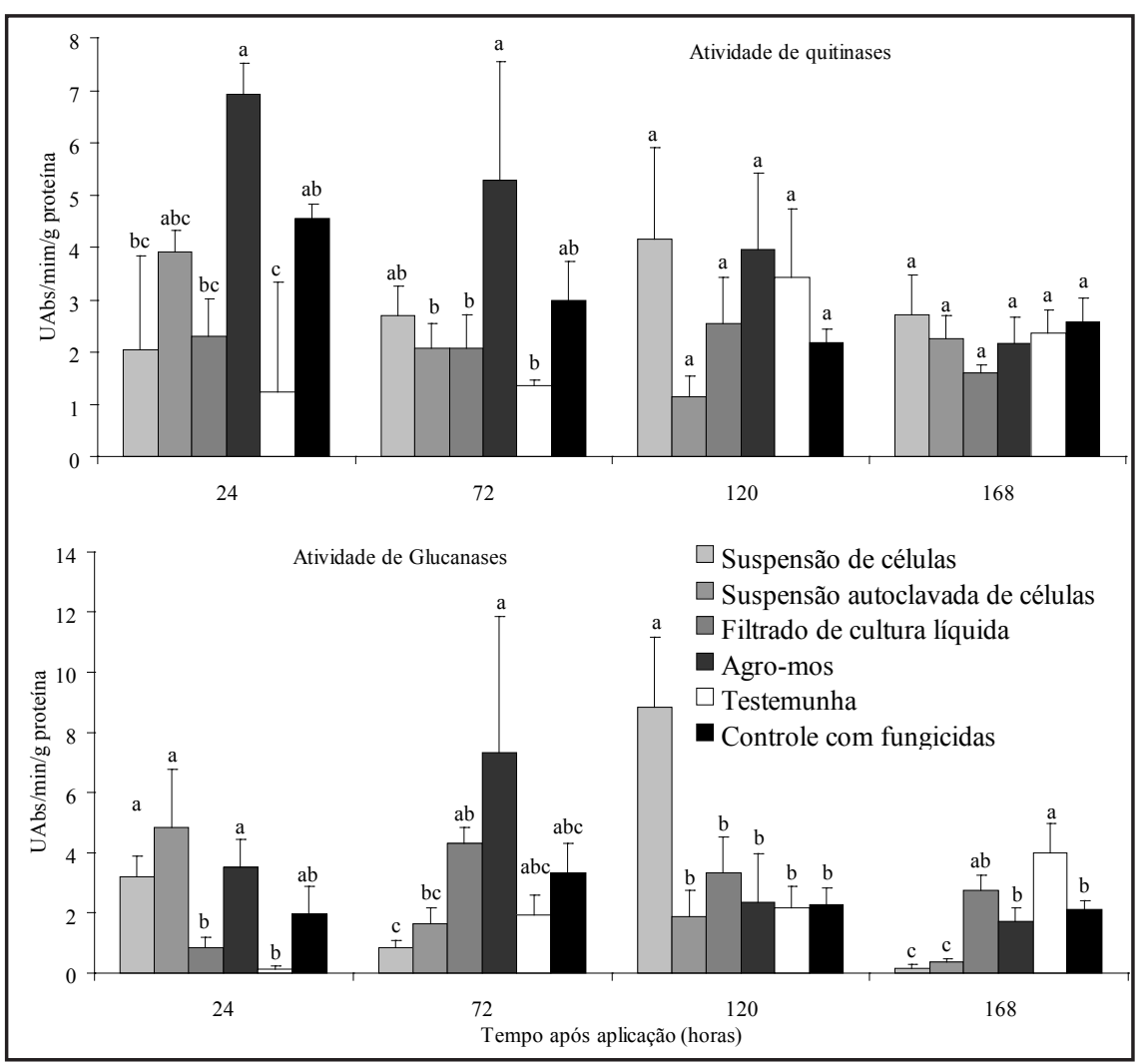

Figura 1. Atividade de quitinases e de $\beta$-1,3-glucanases em morangueiro cultivar Camarosa tratado com diferentes preparações de Saccharomyces cerevisiae (activity of chitinases and $\beta$-1,3-glucanases in strawberry plants, cultivar Camarosa, treated with different preparations of Saccharomyces cerevisiae). Dois Vizinhos, UTFPR, 2004.

o tratamento com suspensão de células não apresentou efeito, reforça a tese de que algum metabólito produzido no processo de crescimento de S. cerevisiae, da ação indireta do tratamento com filtrado de cultura sobre C. acutatum, uma vez que, o meio de cultura pode ter favorecido os microorganismos antagônicos, sobretudo leveduras, presentes nas folhas do morangueiro.

A adição de fontes de nutrientes tais como leite fresco e urina de vaca tem apresentado efeito sobre fitopatógenos pelo estímulo ao controle biológico natural (Bettiol et al., 1999).

Quanto à capacidade de ativar mecanismos de resistência em morangueiro, exceto o tratamento com filtrado de cultura, as preparações de $S$. cerevisiae induziram o aumento da atividade das enzimas relacionadas com a patogênese quitinases e $\beta$-1,3-glucanases (Figura $1)$.

As preparações de $S$. cerevisiae induziram o aumento da atividade das enzimas em momentos diferentes e este aumento não perdurou por muito tempo. Após 120 horas de aplicação dos tratamentos, não houve mais diferença quanto à atividade de quitinases e com relação a $\beta$-1,3-glucanases, 168 horas após a aplicação, os tratamentos que induziram o aumento da atividade desta enzima apresentaram resultados inferiores à testemunha. Isto ocorre, provavelmente, porque a planta além de deixar de expressar resistência, dada a não continuidade do estímulo para síntese da proteína lítica, seja pelo elicitor ou pela presença de um processo infeccioso por um patógeno, pode também ativar mecanismo para degradar a enzima, uma vez que esta se torna desnecessária no tecido vegetal.

O tratamento com AM apresentou os melhores resultados na indução das enzimas, devido, provavelmente, ao maior contato do composto elicitor presente em S. cerevisiae facilitado pelo processo por que passa a levedura para obtenção do produto comercial. O produto também aumentou a atividade de $\beta$-1,3-glucanases em mamão induzindo resistência no tecido do fruto contra podridão provocada por C. gloeosporioides (Dantas et al., 2004).

Comparando-se a atividade de $\beta$-1,3-glucanases entre os tratamentos com suspensão autoclavada de células ou não, observa-se que o tratamento 
Tabela 3. Incidência de mofo-cinzento (Botrytis cinerea) e parâmetros pós-colheita de frutos de morango, cultivar Camarosa, tratado em pré-colheita com diferentes preparações de Saccharomyces cerevisiae (incidence of gray mould (Botrytis cinerea) and postharvest parameters of strawberry fruits, cultivar Camarosa, treated in preharvest with different preparations of Saccharomyces cerevisiae). Dois Vizinhos, UFTPR, 2004.

\begin{tabular}{|c|c|c|c|c|c|}
\hline \multirow{2}{*}{ Tratamentos } & \multicolumn{2}{|c|}{ Incidência de podridão } & \multirow{2}{*}{$\begin{array}{l}\text { Firmeza } \\
\left(\mathrm{N} / \mathrm{cm}^{2}\right)^{*}\end{array}$} & \multirow{2}{*}{$\begin{array}{c}\text { SST } \\
\left({ }^{0} \text { Brix }\right)^{*}\end{array}$} & \multirow{2}{*}{$\begin{array}{c}\text { Acidez } \\
\text { (meq/100 } \mathrm{mL})^{*}\end{array}$} \\
\hline & Com ferimento & Sem ferimento & & & \\
\hline Levedura comercial & $80,0^{\text {ns }}$ & 26,8 bc & $1,75^{\mathrm{ns}}$ & $7,2 \mathrm{a}$ & $6,8^{\text {ns }}$ \\
\hline Suspensão de células & 75,0 & $26,0 \mathrm{bc}$ & 1,66 & $6,8 \mathrm{ab}$ & 7,5 \\
\hline Susp. Autoclav. de células & 80,0 & $32,0 \mathrm{ab}$ & 1,86 & $6,7 \mathrm{~b}$ & 7,2 \\
\hline Filtrado de cultura líquida & 75,0 & $16,8 \quad \mathrm{c}$ & 1,69 & $6,6 \mathrm{~b}$ & 5,8 \\
\hline $\mathrm{AM}$ & 73,9 & $23,3 \mathrm{bc}$ & 2,26 & $7,2 \mathrm{a}$ & 6,7 \\
\hline Testemunha & 60,0 & $46,8 \mathrm{a}$ & 2,07 & $6,0 \quad \mathrm{c}$ & 6,2 \\
\hline Fungicidas & 67,5 & 24,0 bc & 1,67 & $6,0 \quad \mathrm{c}$ & 6,4 \\
\hline CV (\%) & 20,6 & 19,7 & 10,6 & 1,8 & 7,5 \\
\hline
\end{tabular}

Médias seguidas de mesmas letras ou "ns" nas colunas não diferem estatisticamente entre si ao nível de 5\% de significância pelo teste de Duncan; *dados referentes ao experimento para avaliar a incidência de mofo-cinzento (Botrytis cinerea) em frutos de morango sem ferimento artificial, cultivar Camarosa, tratado em pré-colheita com diferentes preparações de Saccharomyces cerevisiae; SST= sólidos solúveis totais ((means followed by the same letter in the column did not differ from each other, Duncan's test, $\mathrm{p}<0,05)$. *data referring to the experiment to evaluate the incidence of gray mould (Botrytis cinerea) in strawberry fruits without artificial wound, cultivar Camarosa, treated in pretharvest with different preparations of Saccharomyces cerevisiae; $\mathrm{SST}=$ total soluble solids). $\mathrm{AM}=\mathrm{Agro}-\mathrm{MOS}{ }^{\circledR} ; \mathrm{Fungicidas}=$ clorotalonil+tiofanato-metílico, folpete e iprodione.

com células não autoclavadas induziu o aumento da atividade da enzima nas avaliações feitas 24 e $120 \mathrm{~h}$ após a aplicação, enquanto que o tratamento com células autoclavadas observou-se apenas $24 \mathrm{~h}$. Comportamento semelhante foi obtido por Roncatto \& Pascholati (1998) na avaliação de diferentes preparações de $S$. cerevisiae observaram que a suspensão autoclavada de células aumentou mais rapidamente a atividade da enzima peroxidase em relação à suspensão não autoclavada.

A capacidade de $S$. cerevisiae induzir resistência sistêmica em plantas está associada a determinados carboidratos e glicoproteínas presentes na parede celular, sendo que a autoclavagem promove uma maior extração, particularmente, de carboidratos sem afetar sua capacidade elicitora (Wulff \& Pascholatti, 1998; Bonaldo, 2005). Assim, o aumento mais rápido na atividade de $\beta$-1,3glucanases induzido pelo tratamento com suspensão autoclavada de células se deu, possivelmente, pelo contato mais rápido do elicitor liberado no processo de autoclavagem, fazendo com que este seja mais rapidamente reconhecido pelo tecido vegetal, enquanto que no tratamento com suspensão não autoclavada o elicitor foi liberado mais tardiamente, na medida em que as células da levedura iam se deteriorando.

S. cerevisiae aumentou a produtividade dos morangueiros, sendo que o melhor desempenho dos tratamentos parece estar associado à capacidade destes de proteger as plantas do ataque de patógenos com preferência por tecidos de flores e frutos, como C. acutatum, uma vez que os tratamentos com menor incidência do patógeno proporcionaram a produção de mais frutos por planta (Tabela 1) e as menores produtividades se deram pelo menor número de frutos colhidos por planta (Tabela 2).

Todos os tratamentos com preparações de $S$. cerevisiae, exceto o tratamento com suspensão autoclavada de células, tiveram efeito sobre a podridão provocada por $B$. cinerea, com incidência de mofo-cinzento inferior ao tratamento testemunha e comparáveis ao tratamento com fungicidas.

O tratamento com filtrado de cultura líquida reduziu $64,1 \%$ e o tratamento com AM 50,2\% a incidência de podridões nos frutos em relação à testemunha (Tabela 3). O fato de que diferentes preparações a partir de $S$. cerevisiae apresentaram efeito sobre a podridão causada por $B$. cinerea em morango indica que a levedura pode atuar por diferentes mecanismos neste patossistema, possivelmente algum metabólito ou complexo de metabólitos produzidos por $S$. cerevisiae pode ter atuado diretamente sobre o patógeno ou sobre um fator de patogenicidade.

No ensaio posterior, onde se avaliou o efeito dos tratamentos realizados na pré-colheita sobre os parâmetros póscolheita, com ferimentos artificiais nos frutos, constatou-se que nenhum dos tratamentos apresentou efeito sobre o mofo-cinzento (Tabela 3). Estes resultados demonstram a importância do cuidado durante a colheita, evitando-se danos mecânicos nos frutos.

Os tratamentos não apresentaram diferença entre si quando avaliados quanto aos parâmetros firmeza de polpa e acidez (Tabela 3). Os tratamentos com preparações de $S$. cerevisiae apresentaram maiores teores de sólidos solúveis totais que os tratamentos testemunha, corroborando os resultados obtidos na avaliação de podridão, uma vez que, a maior incidência de podridão na testemunha, possivelmente acarretou na aceleração do metabolismo nos frutos e, em conseqüência, uma maior degradação do açúcar.

Os resultados indicam que $S$. cerevisiae é um potencial agente de biocontrole, devendo ser conduzidos outros estudos com a levedura, inclusive em associação com outras alternativas, no 
controle de doenças no morangueiro.

\section{REFERÊNCIAS}

BETTIOL W; ASTIARRAGA BD; LUIZ AJB. 1999. Effectiveness of cow's milk against zucchini squash powdery mildew (Sphaerotheca fuliginea) in greenhouse conditions. Crop Protection 18: 489-492.

BONALDO SM. 2005. Efeito de Saccharomyces cerevisiae na sintese de fitoalexinas em sorgo, na germinação e formação de apressórios por fungos fitopatogênicos e na proteção de pepino a Colletotrichum lagenarium e sorgo a Colletotrichum sublineolum. Piracicaba: USP ESALQ. 150p (Tese doutorado).

CARDOSO FILHO JA. 2003. Efeito de Extratos de Albedo de Laranja (Citrus sinensis) dos indutores de resistência ácido salicílico, acilbenzolar-S-Metil e Saccharomyces cerevisiae no controle de Phyllosticta citricarpa (Teleomorfo: Guignardia citricarpa). Piracicaba: USP ESALQ. 125p (Tese doutorado).

CHEAH LH; HUNT AW. 1994. Screening of industrial yeasts for biocontrol of Botrytis storange rot in kiwifruit. In: NEW ZEALAND PLANT PROTECTION CONFERENCE, 47. Anais ... Waitangi: p.362-363.

CHEAH LH; MARSHALL AP. 1995. Biological control of Fusarium storange rot of squash with yeasts. In: NEW ZEALAND PLANT PROTECTION CONFERENCE, 48. Anais ... Hastings: p.337-339.

CHEAH LH; TRAN TB. 1995. Postharvest biocontrol of Penicillium rot of lemons with industrial yeasts. In: NEW ZEALAND PLANT PROTECTION CONFERENCE, 48. Anais ... Hastings: p.155-157.

CIA P. 2005. Avaliação de agentes bióticos e abióticos na indução de resistência e no controle pós-colheita da antracnose
(Colletotrichum gloeosporioides) em mamão (Carica papaya). Piracicaba: USP ESALQ. 197p (Tese doutorado).

DANTAS SAF; OLIVEIRA SMA; BEZERRA NETO E; COELHO RSB; SILVA RLX. 2004. Indutores de resistência na proteção do mamão contra podridões pós-colheita. Summa Phytopathologica 30: 314-319.

FERNANDES-JÚNIOR F; FURLANI PR; RIBEIRO IJA; CARVALHO, C.R.L. 2002. Produção de frutos e estolhos do morangueiro em diferentes sistemas de cultivo em ambiente protegido. Bragantia 61: 25-34.

FIALHO MB; 2004. Efeito in vitro de Saccharomyces cerevisiae sobre Guignardia citricarpa, agente causal da pinta preta dos citros. Piracicaba: USP ESALQ. 60p (Tese mestrado).

GUZZO SD; MARTINS EMF. 1996. Local and systemic induction of $\beta$-1,3-glucanase and chitinase in coffee leaves protected against Hemileia vastatrix by Bacillus thuringiensis. Journal of Phytopathology 144: 449-454.

LOPES EAGL. 2001. Controle biológico de Botrytis cinerea in vitro e em mudas de Eucalyptus sp. Lavras: UFLA. 45p (Tese mestrado).

PICCININ E; DI PIERO RM; PASCHOLATI SF. 2005. Efeito de Saccharomyces cerevisiae na produtividade de sorgo e na severidade de doenças foliares no campo. Fitopatologia Brasileira 30: 5-9.

REICHERT LJ; MADIAL JCM. 2003. Aspectos socioeconômicos. Frutas do Brasil 40: 1215.

RONCATTO MC; PASCHOLATI SF. 1998. Alterações na atividade e no perfil eletroforético da peroxidase em folhas de milho (Zea mays) e sorgo (Sorghum bicolor) tratadas com levedura (Saccharomyces cerevisiae). Scientia Agricola 55: 395-402.

ROVERATTI DS. 1989. Proteção de plantas de café (Coffea arabica L.) contra Hemileia vastatrix Berk. et Br. por Saccharomyces cerevisiae. Piracicaba: USP ESALQ. 94p (Tese mestrado).

SILVA SR; PASCHOLATI SF. 1992. Saccharomyces cerevisiae protects maize plants, under greenhouse conditions, against Colletotrichum graminicola. Journal of Plant Disease and Protection 99: 159-167.

STANGARLIN JR; PASCHOLATI SF. 1994. Proteção de plântulas de milho pipoca contra Exserohilum turcicum pelo uso de Saccharomyces cerevisiae. Summa Phytopathologica 20: 16-21.

STANGARLIN JR; PASCHOLATI SF; LABATE CA. 2000. Efeito de Phaeoisariopsis griseola na atividade de ribulose-1,5-bifosfato carboxilase-oxigenase, clorofilase, $\beta-1,3$ glucanase e quitinase em cultivares de Phaseolus vulgaris. Fitopatologia Brasileira 25: 59-66.

TANAKAMAS; PASSOSFA. 2002. Caracterização patogênica de Colletotrichum acutatum e C. fragariae associados à antracnose do morangueiro. Fitopatologia Brasileira 27: 484-488.

TANAKA MAS; PASSOS FA; BETTI JA. 1997. Resistência de Colletotrichum fragariae e $C$. acutatum ao benomyl na cultura do morango no Estado de São Paulo. Scientia Agricola 54: 139-146.

VAN LOON LC; REP M; PIETERSE CMJ. 2006. Significance of inducible defense-related proteins in infected plants. Annual Review of Phytopathology 44: 135-162.

WIRTH SJ; WOLF GA. 1992. Micro-plate colorimetric assay for endo-acting cellulase, xylanase, chitinase, 1,3- $\beta$-glucanase and amylase extracted from forest soil horizons. Soil Biology and Biochemistry 24: 511-519.

WULFF NA; PASCHOLATISF. 1998. Preparações de Saccharomyces cerevisiae elicitoras de fitoalexinas em mesocótilos de sorgo. Scientia Agricola 55: 138-143. 